\title{
PRÁTICAS SEXUAIS E MORAL NA ANTIGUIDADE E MODERNIDADE, À LUZ DA TEORIA DE MICHEL FOUCAULT
}

\author{
SEXUAL PRACTICES AND MORAL IN ANTIQUITY AND MODERNITY, ACCORDING MICHEL \\ FOUCAULT'S THEORY
}

Thiago Augusto Galeão Azevedo*

\begin{abstract}
RESUMO
Este estudo surge do questionamento sobre a origem das relações de poder exercidas sobre o corpo na modernidade, responsáveis pela própria criação do corpo sexuado e seu controle. A partir de tais noções, nasce o questionamento sobre a ligação do referido controle moderno para com possíveis origens na antiguidade, no que concerne à moral construída sobre o corpo e às práticas sexuais. Para tanto, realizou-se o presente estudo, à luz da teoria do filósofo Michel Foucault, analisando-se em que medida há uma continuidade entre antiguidade e modernidade no que se refere à moral relativa às práticas sexuais. Tem-se como objetivo geral analisar a continuidade da construção moral entre a antiguidade e a modernidade relativa ao corpo e às práticas sexuais desenvolvidas a partir dele. Como hipótese, sustenta-se uma descontinuidade moral entre tais períodos, considerando-se a pastoral cristã como um evento que revolucionou a configuração das relações de poder sobre o corpo.
\end{abstract}

PALAVRAS-CHAVE: Moral. Corpo. Práticas sexuais. Antiguidade. Modernidade.

\begin{abstract}
This study arises from the questioning about the origin of the power relations exercised over the body in modernity, responsible for the very creation of the sexual body and its control. From such notions, the question arises about the connection of the said modern control to possible origins in antiquity, concerning the moral built on the body and sexual practices. To this end, the present study was carried out, in the light of the theory of the philosopher Michel Foucault, analyzing to what extent there is a continuity between antiquity and modernity with regard to the moral relative to sexual practices. The general objective is to analyze the continuity of the moral construction between antiquity and modernity related to the body and the sexual practices developed from it. As a hypothesis, a moral discontinuity is maintained between such periods, considering the Christian pastoral as an event that revolutionized the configuration of power relations over the body.
\end{abstract}

KEYWORDS: Moral. Body. Sexual practices. Antiquity. Modernity.

\footnotetext{
* Mestre em Direito. Professor no Centro Universitário do Pará. E-mail: thiagogaleao@hotmail.com.
} 


\section{INTRODUÇÃO}

A antiguidade e a modernidade são tomadas como momentos paradigmáticos para a compreensão do corpo e das práticas sexuais sustentadas a partir dele em sociedade. Por meio da teoria de Michel Foucault, pretende-se fornecer uma análise sobre a moral construída sobre o corpo e as suas práticas sexuais, em uma interface com a Grécia Clássica, dois primeiros séculos de nossa era e modernidade.

Estudar-se-á a concepção moral construída sobre os objetos do presente estudo na antiguidade e na modernidade, seguindo a ordem do processo investigativo de Michel Foucault, utilizando-se como base, para tanto, a título de revisão bibliográfica, três obras do citado filósofo: História da sexualidade 1: a vontade de saber (2014b); História da sexualidade 2: o uso dos prazeres (2014c) e História da sexualidade 3: o cuidado de si (2014d).

Pretende-se responder à pergunta de pesquisa: em que medida a moral construída sobre as práticas sexuais na modernidade representa uma continuidade em relação à construção moral da antiguidade? Para tanto, o presente artigo está estruturado em duas seções de desenvolvimento, que correspondem aos objetivos de pesquisa.

Como objetivo geral, pretende-se analisar a continuidade da construção moral entre a antiguidade e a modernidade no que concerne ao corpo e as práticas sexuais desenvolvidas a partir dele. Em níveis específicos, almeja-se compreender a configuração moral sobre as práticas sexuais na antiguidade, para que, em seguida, como um segundo objetivo específico, possa-se estudar a relação entre a construção moral sobre as práticas sexuais na antiguidade e na modernidade.

É importante ressalvar que não faz parte do objetivo do presente artigo fazer uma análise sobre a Grécia antiga, propriamente dita. A análise que se sucederá é uma revisitação bibliográfica de Michel Foucault sobre sexualidade na Grécia Clássica e nos dois primeiros séculos de nossa era, mas com o objetivo restrito de entender a linha lógica da teoria do filósofo, que realiza uma volta da modernidade à antiguidade para que a sua teoria passe a ser qualificada em um maior sentido. Logo, não se tem como objetivo estudar esse período, e sim como a teoria de Michel Foucault analisa a sexualidade nele, averiguando-se o seu possível impacto na sua visão teórica da modernidade. 


\section{A CONSTRUÇÃO MORAL SOBRE PRÁTICAS SEXUAIS NA GRÉCIA CLÁSSICA E NOS DOIS PRIMEIROS SÉCULOS DE NOSSA ERA}

É importante deixar claro, desde o início, que Foucault tinha como objetivo realizar um estudo da história da sexualidade enquanto experiência, no sentido de um elemento correlacionado com a cultura, campos de saber, tipos de normatividade e formas de subjetividade. Entretanto, percebeu que essa perspectiva seria insuficiente, uma vez que faria da sexualidade um elemento invariante, diante de não se considerar o seu campo histórico. Por este motivo, Foucault resolveu por retornar, para estudar a sexualidade na Grécia Clássica e nos dois primeiros séculos de nossa era.

Trata-se de uma inversão que no presente estudo é vista como razoável, diante do potencial efeito generalizador de suas análises caso não levasse em consideração as especificidades históricas, especialmente diante de uma estrutura de poder histórica, mas que se projeta de forma a-histórica, natural.

No que concerne à sexualidade, Foucault (2014b) identificou três eixos: a formação dos saberes a que ela se refere, os sistemas de poder reguladores de sua prática e as formas por meio das quais os indivíduos podem e devem se reconhecer como sujeitos dessa sexualidade. Esse terceiro eixo é o que vem a ser desenvolvido no volume dois e três de sua obra História da sexualidade, estudando-se as práticas por meio das quais os indivíduos foram conduzidos a se auto-observarem, a se decifrarem, a se identificarem e se reconhecerem, confessando-se como sujeitos de desejo. O desejo como a chave para a descoberta da verdade de seu ser.

Foucault (2014b) compreendeu que para entender a maneira com que o homem moderno podia fazer a experiência de si próprio como sujeito sexual seria necessário distinguir antes a forma pela qual, durante séculos, o homem ocidental foi levado a se reconhecer como sujeito de desejo. História do homem de desejo.

Pergunta-se o porquê de o comportamento sexual, os prazeres e atividades relacionados a este serem objetos de uma preocupação moral, uma espécie de cuidado ético, que em momentos e sociedades específicas parece ser mais importante do que a atenção moral prestada a outros objetos. Questiona-se: “[...] de que maneira, por que e sob que forma a atividade sexual foi constituída como campo moral? Por que esse cuidado ético tão insistente, apesar de variável em suas formas e em sua intensidade?” (FOUCAULT, 2014c, p. 16). 
Iniciando a análise sobre a Grécia Clássica, século IV a. C, no que concerne ao campo da atividade sexual, pode-se destacar, inicialmente, as chamadas artes da existência ou técnicas de si, que nas palavras de Foucault (2014c, p. 16) seriam:

[...] práticas refletidas e voluntárias através das quais os homens não somente se fixam regras de conduta, como também procuram se transformar, modificar-se em seu ser singular e fazer de sua vida uma obra que seja portadora de certos valores estéticos e responda a certos critérios de estilo.

As citadas artes da existência perderam, indubitavelmente, uma parte de sua importância e de sua autonomia a partir do Cristianismo, sendo integradas a uma lógica de poder pastoral, seguida de práticas de tipo educativo, médico ou psicológico. Entretanto, é de fundamental importância realizar o estudo histórico dessa estética da existência e tecnologias de si, à luz da teoria de Michel Foucault, para a compreensão do objeto do presente estudo.

No pensamento antigo, no âmbito da reflexão moral da antiguidade, pode-se destacar a formação de quatro temáticas relativas à austeridade sexual, são elas: vida do corpo, instituição do casamento, relações entre homens e a existência de sabedoria. Estas como consubstanciações de uma elaboração e estilização de uma atividade na prática de sua liberdade, e no exercício de seu poder. Trata-se de regiões da experiência nas quais o comportamento sexual foi problematizado, tornando-se um objeto de cuidado, reflexão, matéria de estilização (FOUCAULT, 2014c).

O comportamento sexual foi objeto de reflexão como domínio de experiência moral ${ }^{1}$. Passar-se-á a analisar, pontualmente, elementos que compuseram esse domínio de experiência moral e que possuem uma relação com o objeto deste artigo. Uma análise de comportamentos, valores e regras de ação que compunham a moral da época no que concerne ao âmbito dos

\footnotetext{
${ }^{1}$ Nesta seção, quando se fala em moral se adota o seguinte valor: "Por 'moral' entende-se um conjunto de valores e regras de ação proposto aos indivíduos e aos grupos por intermédio de aparelhos prescritivos diversos, como podem ser a família, as instituições educativas, as Igrejas etc. Acontece de essas regras e valores serem bem explicitamente formulados numa doutrina coerente e num ensinamento explícito. Mas acontece também de elas serem transmitidas de maneira difusa e, longe de formarem um conjunto sistemático, constituírem um jogo complexo de elementos que se compensam, se corrigem, se anulam em certos pontos, permitindo, assim, compromissos ou escapatórias. Com essas reservas pode-se chamar 'código moral' esse conjunto prescritivo. Porém por 'moral' entende-se igualmente o comportamento real dos indivíduos em relação aos valores e regras que lhes são propostos: designa-se, assim, a maneira pela qual eles se submetem mais ou menos completamente a um princípio de conduta; pela qual eles obedecem ou resistem a uma interdição ou a uma prescrição; pela qual eles respeitam ou negligenciam um conjunto de valores; o estudo desse aspecto da moral deve determinar de que maneira, e com que margens de variação ou de transgressão, os indivíduos ou grupos se conduzem em referência a um sistema prescritivo que é explícita ou implicitamente dado em sua cultura, e do qual eles têm uma consciência mais ou menos clara. Chamemos a esse nível de fenômenos a 'moralidade dos comportamentos'. " (FOUCAULT, 2014c, p. 32-33).
} 
prazeres sexuais, a chamada aphrodisia, considerando que no vocabulário da antiguidade não havia uma palavra que correspondesse especificamente ao termo sexualidade. Os gregos, entretanto, não se importaram em seu testemunho histórico, nem mesmo em sua reflexão prática, em delimitar o que exatamente entendiam por aphrodisia.

Inicialmente, no âmbito da moralidade dos comportamentos relacionados aos prazeres sexuais (aphrodisia), ressalta-se que o que distinguia, na época, os homens entre si, tanto em um âmbito médico como moral, não era tanto o modo de prática sexual que eles preferem, mas sim a intensidade dessa prática. Trata-se de uma lógica de moderação e incontinência. Logo, para Foucault (2014c), no campo do comportamento sexual, a partir de uma perspectiva moral, foi traçada inicialmente uma linha de divisão que estava pautada na atividade e nas suas gradações quantitativas.

\footnotetext{
- Se a repressão já existia durante a Antiguidade, qual foi a forma e que mudanças puderam ser observadas?

- Essa repressão se manifestou em um contexto totalmente diferente. O problema de moral que é tratado nos textos clássicos diz respeito à libido, e não ao comportamento sexual. Pergunta-se como se dominar a si mesmo e como evitar as reações violentas para com outros. Para o comportamento sexual, existe certo número de regras, mas elas não são manifestamente muito importantes. Sente-se muito bem que o problema geral de ética não concerne à sexualidade. O problema desliza para a libido, eis uma contribuição do cristianismo e mais particularmente do monasticismo. Vemos aparecerem dois problemas em estreita relação: o problema da gulodice e o da sexualidade. Como evitar comer demais e como controlar as pulsões que para um monge não são o contato sexual com outro, mas o próprio desejo sexual, a alucinação sexual, a sexualidade como relação de si consigo, acompanhada de manifestações tais como a imaginação, os devaneios... (FOUCAULT, 2014a, p. 243).
}

Não havia, destaca-se, uma noção comum que pudesse externar o que há de específico na sexualidade masculina e feminina. A prática dos prazeres sexuais distinguia claramente dois papéis e polos: sujeito e objeto, agente e paciente. A fêmea seria o objeto de um elemento ativo, de um agente, de um sujeito: o macho. A atividade aphrodisia é exercida pelo macho sobre a fêmea, que seria seu objeto. Trata-se da linha de demarcação entre homens e mulheres, diante da forte diferenciação entre eles em muitas sociedades antigas.

Podem-se identificar agentes ativos e objetos, diante de sua passividade. Os primeiros seriam os homens, mais precisamente os adultos e livres. Os segundos, as mulheres, mas estas apenas como elementos de um conjunto mais amplo, que inclui escravos e rapazes, estes como objetos de um prazer possível. 
Assim, a segunda variável relacionada à imoralidade na prática da aphrodisia é a passividade. $\mathrm{O}$ excesso relacionado à prática sexual e a passividade são dois fatores que qualificam um homem como imoral. São as duas principais formas de imoralidade na prática da aphrodisia.

\begin{abstract}
Manter-se em seu papel ou abandoná-lo, ser sujeito da atividade ou dela ser objeto, passar para o lado daqueles que sofrem quando se é um homem, ou permanecer no lado daqueles que a exercem, eis a segunda grande variável que, juntamente com a da 'quantidade de atividade', alimenta a apreciação moral. O excesso e a passividade são, para um homem, as duas formas principais de imoralidade na prática dos aphrodisia. (FOUCAULT, 2014c, p. 58-59).
\end{abstract}

A atividade sexual não é considerada um mal em si mesmo. Pelo contrário, é encarada, de forma geral, como natural e indispensável, uma vez que é por meio dela que os seres vivos podem se reproduzir, que a espécie de uma forma coletiva escapa da morte e que "[...] as cidades, as famílias, os nomes e os cultos podem se prolongar muito além dos indivíduos destinados a desaparecer" (FOUCAULT, 2014c, p. 59).

Este caráter passivo e reprodutivo é atribuído à figura da mulher. Foucault denuncia que a mulher era considerada, por natureza, passiva, diferente do homem que tem como papel o controle, a atividade. O homem era marcado pelo domínio de si. Em outras palavras, ele deve comandar, obrigando à obediência o que não possui capacidade de se autodirigir, impondo-se princípios racionais àqueles que seriam desprovidos destes, como a mulher [sic]. Trata-se do caráter viril da temperança.

\begin{abstract}
O domínio de si é uma maneira de ser homem em relação a si próprio, isto é, comandar o que deve ser comandado, obrigar à obediência o que não é capaz de se dirigir por si só, impor os princípios da razão ao que desses princípios é desprovido; em suma, é uma maneira de ser ativo em relação ao que, por natureza, é passivo e que deve permanecê-lo. Nessa moral de homens feita para os homens, a elaboração de si como sujeito moral consiste em instaurar de si para consigo uma estrutura de virilidade: é sendo homem em relação a si que se poderá controlar e dominar a atividade de homem que se exerce em face dos outros na prática sexual. [...]. No uso desses prazeres de macho é necessário ser viril consigo como se é masculino no papel social. A temperança é, no sentido pleno, uma virtude de homem. (FOUCAULT, 2014c, p. 99, grifo nosso).
\end{abstract}

A passividade como um atributo feminino, da mulher, porém não é exclusivo desta; pode ser estendido a rapazes e escravos, entretanto, estes eram considerados imorais diante de sua passividade, porque era contra a sua natureza este tipo de comportamento. A passividade 
como um atributo natural e que assim deveria permanecer, conforme Foucault (2014c) denuncia no trecho retro transcrito.

Não se percebe, entretanto, uma vinculação da figura do homem e da mulher à sua genitália. Trata-se de um contexto lógico de atividade/passividade, que seriam atribuídos ao homem e à mulher, respectivamente, mas sem julgá-los a partir de uma genitália. Tanto que, no período e moral em análise, a relação de dois homens era qualificada de uma forma específica e distinta da modernidade, no sentido de que aquele que penetra um outro homem não é julgado como imoral, mas como um ser que está exercendo o seu papel natural de penetrador. Trata-se de uma questão de ser ativo no coito sexual e ter o domínio de seus instintos, de si. Uma perspectiva diversa do pecado e controle implantados pela pastoral cristã.

No que concerne a rapazes e escravos que assumissem um papel passivo em relação aos prazeres sexuais, estes eram considerados imorais, desvalorizados. Há uma lógica de contaminação do masculino (ativo) por um atributo que não seria próprio dele, a passividade, vinculada naturalmente ao feminino. Logo, eles eram considerados imorais porque não reproduziram uma lógica natural.

\footnotetext{
Numa experiência da sexualidade como a nossa, em que uma cesura fundamental opõe o masculino e o feminino, a feminidade do homem é percebida na transgressão efetiva ou virtual de seu papel sexual. Ninguém será tentado a dizer de um homem cujo amor às mulheres o leva ao excesso que ele seja efeminado - a não ser operando sobre o seu desejo todo um trabalho de decifração e desentocando 'a homossexualidade latente' que habita em segredo sua relação instável e multiplicada com as mulheres. Ao contrário, para os gregos, é a oposição entre atividade e passividade que é essencial e marca tanto o domínio dos comportamentos sexuais como das atitudes morais; vê-se, então, por que um homem pode preferir os amores masculinos sem que ninguém sonhe em suspeitá-lo de feminidade, desde que ele seja ativo na relação sexual e ativo no domínio de si; em troca, um homem que não é suficientemente dono de seus prazeres - pouco importa a escolha de objeto que faça - é considerado 'feminino'. (FOUCAULT, 2014c, p. 101-102, grifos nossos).
}

A feminidade do homem representava uma transgressão ao seu papel sexual. Um homem poderia se relacionar com outros homens, sem ter um caráter feminino, desde que fosse ativo na relação sexual e ativo no domínio de si, senão era considerado feminino e, consequentemente, imoral, uma vez que violou a sua própria natureza. Era admitido como manifestamente natural ter prazer com um rapaz; o que era muito mais difícil de se aceitar como natural era aquilo que faz do rapaz um objeto de prazer, já que se estaria diante de uma feminização de um dos parceiros (FOUCAULT, 2014c). 
Foucault ressalta o princípio do isomorfismo entre relação sexual e social. Esse princípio coloca em paridade a relação sexual de um homem e uma mulher com a relação social firmada entre eles. Especificamente, a relação sexual, moralmente à época, já era vista sob a lógica da penetração, este como um ato diferenciador de um homem em relação a uma mulher, o que propiciava uma polaridade opositora entre passividade e atividade.

Essa relação sexual é concebida como paralela, do mesmo tipo, que a relação de superioridade e inferioridade, entre aquele que domina e é dominado (homem e mulher). Aquele que é o ativo, o homem, que penetra, é o superior, detentor da honra. Enquanto a mulher é a penetrada, desprovida dessa superioridade. Todavia, um ponto muito importante merece ser destacado. A passividade da mulher era um reflexo da inferioridade de sua natureza e condição [sic], não merecendo ser reprovada ou mesmo considerada imoral, pois não foi um ato de escolha ser passivo em uma relação e sim fruto de sua natureza.

\footnotetext{
No que diz respeito à passividade da mulher, ela marca muito bem uma inferioridade de natureza e de condição; mas ela não deve ser reprovada como conduta, posto que é, precisamente, conforme ao que a natureza quis e ao que o status impõe. Em compensação, tudo aquilo que no comportamento sexual poderia acarretar para um homem livre - e ainda mais para um homem que, por sua origem, fortuna, prestígio, ocupa ou deveria ocupar posições privilegiadas entre os demais as marcas da inferioridade, da dominação sofrida, da servidão aceita, só poderiam ser consideradas vergonhosas: e vergonha ainda maior se ele se presta a ser objeto complacente do prazer do outro. (FOUCAULT, 2014c, p. 264, grifos nossos).
}

Natureza. Na moralidade dos comportamentos da Grécia Clássica se pode identificar uma relação da mulher com a natureza. A mulher era naturalmente inferior ao homem, uma vez que ela era quem recebia a penetração deste. O ser que era naturalmente penetrado.

Ser mulher, naturalmente, era ser penetrada. Quanto aos homens, estes eram considerados, conforme denuncia Foucault (2014c, p. 272), como indivíduos que procuram imitar a mulher: “"Todo mundo reprovará a lassidão daquele que cede aos prazeres e que não pode resistir' e 'naquele que procura imitar a mulher, todo mundo reprovará a imagem demasiado semelhante à dela que ele assume"”.

Além da passividade moralmente atribuída à figura da mulher, na Grécia Clássica, pode-se ressaltar um segundo fator que era próprio do feminino: a reprodução. Foucault denuncia a lógica dominante nesse contexto, a de que a natureza organizou a conjunção dos sexos para propiciar a descendência dos indivíduos, consequentemente a sobrevivência da espécie humana. 
O cuidado com a progenitura também motiva a vigilância que se deve manifestar no uso dos prazeres. Pois, ao admitir-se que a natureza organizou a conjunção dos sexos para assegurar a descendência dos indivíduos e a sobrevivência da espécie, ao admitir-se também que por essa mesma razão ela associou à relação sexual um tão vivo prazer, reconhece-se que essa descendência é frágil, pelo menos em sua qualidade e seu valor. É perigoso, para o indivíduo, obter seu prazer ao acaso; mas se é ao acaso que ele procria, e não importa como, o futuro de sua família é colocado em perigo. (FOUCAULT, 2014c, p. 159).

Eis um contexto moral regido pela regra da procriação, que prega que para o indivíduo não se tornar um ser sem renome, sem nome, as leis dizem que este deve se casar e dar uma descendência, nas melhores condições possíveis (FOUCAULT, 2014c). A descendência seria a responsável pela transcendência à morte. Ao ser humano lhe é destinado a morte, entretanto, a progenitura seria o instrumento responsável pela fuga àquela. $\mathrm{O}$ homem escapa à morte por meio de sua descendência.

A atividade sexual se inscreve, portanto, no amplo horizonte da morte e da vida, do tempo, do vir a ser e da eternidade. Ela se torna necessária porque o indivíduo é destinado a morrer e para que, de certa maneira, ele escape à morte. É claro que essas especulações filosóficas não estão diretamente presentes na reflexão sobre o uso dos prazeres e sobre o seu regime. (FOUCAULT, 2014c, p.165).

Foucault (2014c) ressalta ainda que esse tipo de concepção, justificando o indivíduo e a espécie em uma lógica de tempo e eternidade, vida e morte, é determinante na boa aceitação das prescrições reguladoras da atividade sexual pelos cidadãos.

O filósofo em foco realiza, ainda, uma análise sobre o desenvolvimento, nos dois primeiros séculos de nossa era, da arte da existência criada pelos gregos, na antiguidade clássica, em sua obra História da sexualidade 3: o cuidado de si (2014d). Passar-se-á a desenvolver pontos específicos da configuração moral destes dois séculos, correlacionando-os com o que foi analisado sobre a Grécia Clássica.

Foucault sustenta, no primeiro capítulo do citado livro, a obra $A$ chave dos sonhos, de Artemidoro, este como o único texto restante na íntegra de uma literatura abundante na Antiguidade: a literatura da onirocricia, século II d. C. Artemidoro afirma que não teve nenhuma outra atividade que não seja se dedicar integralmente à interpretação dos sonhos.

Referindo-se a sonhos, Artemidoro realiza uma interpretação envolvendo dois homens. Foucault (2014d) afirma que Artemidoro privilegia a relação pautada na penetração, o que coloca a relação entre mulheres na categoria de atos fora da natureza, enquanto as relações entre homens não. A lógica funciona da seguinte forma: a relação entre dois homens 
é marcada pela penetração, que seria o ato viril por excelência, este não é em si mesmo uma violação da natureza, uma vez que seria própria à essência do homem penetrar, entretanto ser penetrado, não. Por isso, nessa relação há um homem que será considerado vergonhoso, inconveniente. Entretanto o ato de penetrar não seria considerado transgressor da natureza, enquanto o ser penetrado sim.

No que concerne ao relacionamento entre mulheres, Artemidoro julga ser violadora da natureza essa relação, devido ao fato de que uma mulher estaria, por meio de um algum artifício, usurpando o papel do homem, tomando de forma abusiva a sua posição, possuindo uma outra mulher.

\footnotetext{
Em troca, entre duas mulheres um tal ato que se efetua a despeito daquilo que elas são, e com recurso a subterfúgios, é tão fora da natureza como a relação entre um humano com um deus ou com um animal. Sonhar com esses atos significa que se terá atividades vãs, que se irá separar-se do marido, ou que se ficará viúva. A relação entre as duas pode também significar a comunicação ou o conhecimento dos 'segredos' femininos. (FOUCAULT, 2014d, p. 32).
}

Nos escritos de Artemidoro, à luz de Michel Foucault (2014d), a penetração constitui a essência da prática sexual, como o qualificador dos atos sexuais, a partir de suas variantes: passivo ou ativo. É a penetração o aporte de análise de qualquer ato sexual, quem está no polo ativo ou passivo da prática sexual. Deve-se saber quem penetra e quem é penetrado. A natureza, de acordo com a moral dos prazeres da época, continuava a estabelecer que o homem é o ser penetrante, enquanto a mulher o ser penetrável.

\footnotetext{
Em relação ao que se passa entre essas personagens e o sonhador, a sobriedade de Artemidoro é extraordinária. Não há carícias, combinações complicadas, nem fantasmagorias; mas algumas variações bem simples em torno de uma forma essencial, a penetração. É ela que parece constituir a própria essência da prática sexual, em todo caso, a única que merece ser retida, e que faz sentido para a análise do sonho. Muito mais que o próprio corpo, com suas diferentes partes, muito mais do que o prazer com suas qualidades e intensidades, o ato de penetração aparece como qualificador dos atos sexuais, com algumas de suas variantes de posição e sobretudo seus dois polos de atividade e de passividade. (FOUCAULT, 2014d, p. 37).
}

Foucault (2014d, p. 133) comenta, também, as análises de Galeno em relação a aphrodisia, que estariam situadas dentro da temática antiga das relações entre morte, imortalidade e reprodução. $\mathrm{O}$ autor sustenta que para Galeno, assim como para toda uma tradição filosófica, é “[...] na falta de eternidade que se enraíza a necessidade da separação dos sexos, a intensidade de sua atração recíproca e a possibilidade da geração". 
Em outras palavras, a necessidade de separação dos sexos estaria fundamentada na finitude da vida. Trata-se de uma lógica que estaria pautada na ideia de que como o ser humano é finito em termos de vida; para que a sua espécie não seja exterminada diante dessa finitude, os sexos foram divididos, de uma forma que se completam por meio da geração, por meio da progenitura.

Uma lógica de que para se vencer a morte, dividiram-se os sexos, propiciando a estes atrações recíprocas, tornando-se, portanto, a morte um fenômeno vencido pela vida. Macho e fêmea. Os sexos estariam fundamentados na reprodução, na progenitura.

Foucault (2014d) sustenta que Galeno encara como um desafio assegurar a salvação e a proteção da espécie humana. Seria necessário algo engenhoso. Para tanto, Galeno sustenta que Demiurgo ao dar origem aos seres vivos, dando-lhes um meio para se reproduzirem, precisou aplicar uma "artimanha" diante da corruptibilidade da matéria, por meio da qual este mundo é feito, que estaria pautada em três elementos: 1. Os órgãos que são dados a todos os seres vivos, que servem para a fecundação; 2. Uma capacidade de prazer extraordinária; 3. E no âmbito da alma, o desejo de se servir desses órgãos.

Aos seres vivos, portanto, ser-lhes-iam dados órgãos que têm como finalidade a reprodução, associado ao prazer extraordinário obtido em uma relação sexual que seria o caminho para a progenitura, isto em uma lógica homem e mulher, pênis e vagina. Ademais, os seres humanos ainda seriam marcados por um desejo de fazer uso desses órgãos com fins de reprodução. Um desejo forte o bastante que não teria a necessidade de ser percebido. Como sustenta Foucault (2014d, p. 135): “Os aphrodisia, por sua vivacidade, servem a uma razão que aqueles que a praticam nem mesmo têm necessidade de conhecer.”.

Assim, o desejo, o prazer obtido entre um homem e uma mulher, por meio da penetração completada pela ejaculação, estaria justificado pela obtenção da procriação. Tratase de um elemento que estaria vinculado à natureza, supostamente uma obra da natureza, por isso a divisão dos sexos.

Galeno, de acordo com Foucault (2014d), sustenta uma fisiologia dos atos sexuais que estaria marcada por elementos que se poderia identificar em tradições anteriores. Em Galeno, o aparelho anatômico da mulher seria semelhante ao avesso do homem. Ele supõe que a mulher emitiria esperma assim como o homem; entretanto, a diferença estaria na concepção de que essa emissão na mulher seria menos perfeita e menos completa da que realizada pelo homem, o que justificaria o papel menor da mulher na formação do embrião. 
Foucault (2014d) destaca, ainda, que Galeno trata de uma espécie de "fisiologização" do desejo e do prazer. O capítulo nove de sua obra XIV Do uso das partes suscita a seguinte questão: "Por que um tão vivo gozo é ligado ao uso das partes genitais?" (GALENO apud FOUCAULT, 2014d, p. 136). Trata-se de uma violência do desejo, que tem a sua intensidade ligada a uma finalidade. Para Galeno, essa finalidade não seria apenas para impulsionar os atos sexuais e sim a progenitura, a continuidade de gerações.

E logo Galeno rejeita a ideia de que a violência do desejo e sua intensidade poderiam estar simplesmente associadas, pela vontade de seus criadores, ao ato sexual, como um motivo sugerido aos homens para a ele impulsioná-los. Galeno não nega que o poder demiúrgico fez de sorte que exista essa vivacidade que nos impele: ele quer dizer que ela não foi acrescentada na alma como um suplemento, mas sim que ela foi verdadeiramente inscrita como consequência dos mecanismos do corpo. Desejo e prazer são diretamente os efeitos de disposições anatômicas e dos processos físicos. A causa final - que é a continuação de gerações - é perseguida através de uma causa material e um arranjo orgânico: 'Se esse desejo, se esse gozo existem nos animais, não é somente porque os deuses criadores do homem quiseram lhes inspirar um violento desejo do ato venéreo ou vincular a uma realização um vivo gozo; mas porque eles dispuseram a matéria e os órgãos para obter esses resultados'. (FOUCAULT, 2014d, p. 136, grifos nossos).

Na concepção de Galeno, portanto, à luz de Michel Foucault (2014d), o desejo e o prazer são derivados de uma relação com a natureza. Estão diretamente relacionados com a disposição anatômica com que o indivíduo nasce. Trata-se de uma lógica de prazer e desejo naturalmente recíprocos, diante de serem marcados por uma finalidade comum: a procriação.

Essa perspectiva pode ser observada, também, em Cáricles, por meio do que sustenta Michel Foucault (2014d), ao tratar da sequência das gerações. Com fins de vencer o limiar da vida, a morte, naturalmente se teria determinado a partilha dos sexos, sendo um o responsável por espalhar o sêmen e o outro a recebê-lo, estando marcados por um desejo recíproco.

Sabendo que os seres vivos eram feitos 'de uma matéria perecível', e que o tempo determinado para cada ser era breve, ela arranjou (emechanesato) as coisas de tal maneira que a destruição de um seja o nascimento do outro: assim, através do jogo das sucessões, podem viver até a eternidade. Para isso, ela ordenou ainda a partilha dos sexos, um destinado a espalhar o sêmen, o outro a recebê-lo; e ela verteu em cada um deles o apetite (páthos) pelo outro. Da relação desses dois sexos diferentes pode nascer a sequência das gerações - mas nunca da relação entre dois indivíduos de mesmo sexo. Assim, Cáricles ancora solidariamente, na ordem geral do mundo, lá onde estão ligadas entre si a morte, a geração e a eternidade, a natureza própria de cada sexo e o prazer que convém a cada um deles. Não convém que 'o feminino' se faça de macho, contra a natureza; nem que o 'masculino, indecentemente, se efemine'. Ao querer escapar dessa determinação não se estaria transgredindo apenas os caracteres próprios aos indivíduos; se estaria prejudicando o encadeamento da necessidade universal. (FOUCAULT, 2014d, p. 267, grifos nossos).

Sapere aude - Belo Horizonte, v. 11 - n. 21, p. 239-258, Jan./Jun. 2020 - ISSN: 2177-6342 
Mais uma vez, pode-se perceber que o feminino e o masculino, o ser mulher e o ser homem, estão associados diretamente à lógica da procriação. Naturalmente, separaram-se os sexos para que eles, a partir de uma relação sexual marcada por prazer e desejo, procriem.

Essa lógica de procriação que marca a relação entre um homem e uma mulher estaria firmada em uma perspectiva de casamento. Citando Musonius, Foucault (2014d) destaca que esse instituto estaria atravessado por dois efeitos, que seriam intrínsecos: formação de uma descendência comum e companheirismo de vida. Em Musonius, o criador, após ter separado os dois sexos, implantou nestes um violento desejo, com fins de reaproximá-los, um desejo concomitante de conjunção e de união.

Robustecendo essa perspectiva moral da época, Foucault (2014d) cita, também, Hierocles, quem fundamenta o instituto do casamento na natureza binária. Segundo ele, o ser humano é binário por constituição. Possui em sua essência a vivência a dois, em uma relação que tenha o condão de lhe gerar uma descendência e lhe permita a vitaliciedade com um parceiro. O homem como um ser conjugal.

É importante situar, mesmo que brevemente, o contexto em relação ao qual se está analisando, os dois primeiros séculos de nossa era. Michel Foucault (2014d) ressalta uma severidade testemunhada nos textos de Soranus e de Rudo de Éfeso, de Musonius ou de Sêneca, de Plutarco, Epicteto ou de Marco Aurélio. Uma moral que foi tomada emprestada por autores cristãos, de forma explícita e implícita. Em relação à Grécia Clássica, tornou-se mais forte e insistente a questão dos prazeres, no sentido de uma inquietação em relação aos prazeres sexuais. Uma problematização mais intensa dos aphrodisia.

Foucault (2014d) sustenta, entretanto, que apesar de uma nítida maior severidade, rigor expresso pelos moralistas, não se formou uma demanda de intervenção por parte do poder público. Não se encontrará, portanto, nos filósofos um projeto para uma legislação coercitiva e geral dos comportamentos sexuais. Em compensação, o que pode ser observado nos textos dos dois primeiros séculos é a importância de se dar atenção a si próprio. Trata-se do chamado cuidado de si.

Uma majoração da austeridade sexual na reflexão moral, mas que não ganha a forma de um incremento da rigidez do código que define os atos proibidos, e sim de uma intensificação da relação do indivíduo consigo mesmo, este como sujeito de seus atos. Eis uma cultura de si que foi marcada pelo aumento do cuidado médico, atravessado pela lógica de atenção com o corpo, elemento este diretamente relacionado à alma. 
Os males do corpo e da alma podem se comunicar entre si e contaminar um em relação ao outro com seus mal-estares. Nesse sentido, “[...] lá, onde os maus hábitos da alma podem levar a misérias físicas enquanto os excessos do corpo manifestam e sustentam as falhas da alma" (FOUCAULT, 2014d, p. 73). Deve-se corrigir a alma se se almeja que o corpo não prevaleça sobre ela, assim como se deve retificar o corpo se se almeja que a alma mantenha o domínio integral sobre si mesma. Trata-se, portanto, de um corpo frágil, vulnerável, que ameaça a alma diante de suas próprias fraquezas.

No âmbito da moral dos prazeres, em relação a esse contexto de cuidado de si, deve-se atentar para as transformações que puderam afetar essa moral. No campo das proibições não houve nenhum tipo de ampliação, nem mesmo o interesse de se organizarem sistemas de proibições mais autoritários e invasivos. A mudança no âmbito moral do sujeito está situada principalmente na maneira pela qual o indivíduo deve se constituir enquanto sujeito moral. (FOUCAULT, 2014d).

O prazer sexual continua sendo uma substância ética marcada pela força. Trata-se de uma força contra a qual é necessário lutar. O sujeito deve assegurar sua dominação, podendose fazer uma associação com a lógica de temperança, do autocontrole, já analisados quando se estudou a lógica moral das práticas sexuais na Grécia Clássica.

Houve uma alteração no campo do trabalho que se deve exercer sobre si próprio, a partir da cultura de si. Por meio de exercícios de abstinência e de domínio, o lugar atribuído ao conhecimento de si se tornou mais importante, eis a "[...] tarefa de se pôr à prova, de se examinar, de controlar-se numa série de exercícios bem-definidos [...]" (FOUCAULT, 2014d, p. 87). Trata-se, consequentemente, ainda, de uma soberania do indivíduo sobre si próprio, mas que foi ampliada, para além tão somente de uma dominação do indivíduo sobre seus desejos, por exemplo, mas de um gozo sem desejo e sem perturbação.

Sendo assim, fazendo-se uma análise paralela entre a moral vigente na Grécia Clássica e nos dois primeiros séculos de nossa era, à luz de Foucault, pode-se identificar uma permanência, continuidade, dos princípios gerais.

De modo geral, todos esses temas da dietética permaneceram extraordinariamente contínuos desde a época clássica; os princípios gerais, como vemos, foram mantidos; no máximo, eles foram desenvolvidos, detalhados e aprimorados; eles propõem um ajuste da vida mais estrito e solicitam da parte daqueles que querem observá-los uma atenção ao corpo mais constantemente vigilante. (FOUCAULT, 2014d, p. 132). 
Porém, ainda se está longe, nos dois primeiros séculos, de um contexto moral no qual os prazeres sexuais serão dotados de um mal, fazendo com que os comportamentos devam se submeter à forma universal da lei. Uma lógica marcada pela decifração dos desejos como prérequisito para uma existência purificada. Trata-se da pastoral cristã , que exercerá uma influência direta na concepção moral dos prazeres sexuais.

\section{PRÁTICAS SEXUAIS NA ANTIGUIDADE E MODERNIDADE: DESCONTINUIDADE E ESPECIFICIDADES}

Foucault (2014d) faz uma ressalva de fundamental importância. Poder-se-ia, a partir da identificação de traços comuns, ter a impressão de que a ética sexual própria ao cristianismo, ou Ocidente moderno, já estaria instaurada a partir de alguns de seus princípios essenciais na época em que estava em vigência a cultura greco-romana. Todavia, ressalva Foucault, esse pensamento seria marcado por um desconhecimento de distinções fundamentais próprias às relações que os indivíduos sustentavam consigo mesmos.

Perceber-se-ão as citadas distinções fundamentais, a partir da Idade Média. Tudo passou a ser regulado, das posições sexuais até os sonhos dos indivíduos, precisava-se saber de tudo.

Começa-se a entender, assim, a ressalva de Foucault quanto ao possível pensamento de que a ética sexual moderna já teria alguns de seus princípios fundamentais na vigência da moral da Grécia Clássica. Passou-se de uma lógica de cuidado de si, que não estaria marcada por um aspecto de controle, para um contexto dominado pela pastoral cristã, atravessado por uma configuração de poder extremamente controladora, o que influenciou diretamente na relação do corpo, sexo e gênero.

\footnotetext{
A essa discrição grega se oporá a meticulosidade atenta da pastoral cristã, a partir da Idade Média: então se fará com que tudo seja regulado - posições, frequência, gestos, estado de alma de cada um, conhecimento por uma das intenções do outro, signos do desejo por um lado, marcas de aceitação por outro etc. A moral helenística e romana, por seu lado, diz pouco sobre isso. (FOUCAULT, 2014d, p. 206).
}

Portanto, é importante destacar que não se pode inferir que a moral sexual própria ao cristianismo e a do paganismo formem uma continuidade. Há diversos princípios, noções e temáticas que podem ser encontradas tanto em um como em outro, mas não possuem o mesmo lugar e valor em ambos. A igreja e a pastoral cristã colocaram em vigência um 
princípio moral constritivo, controlador, que possuía um alcance universal. Todavia, na antiguidade, o pensamento não estava organizado sob o viés de uma moral unificada, coerente e impositiva a todos. Tratava-se apenas de uma suplementação à moral aceita comumente (FOUCAULT, 2014c).

Pode-se falar de relações de poder sobre o corpo em um período moderno, a partir do qual o corpo foi criado e utilizado como instrumento de controle de vidas. Um novo mecanismo de poder centrado na vida, que se desenvolveu através de duas formas: Poder disciplinar e Biopolítica das populações, esta subdividida em governamental estatal e econômica neoliberal.

A primeira forma de poder incidente sobre a vida, à luz da teoria de Michel Foucault, é o chamado Poder disciplinar, que tem como objeto de incidência o corpo, este em uma lógica individual. Os corpos ficam expostos a essa forma de poder, ganhando um status econômico. Passa-se a relacioná-lo a uma máquina, que precisa ser controlada, domesticada, ter horários de funcionamento, uma meta de produção e um padrão de comportamento. Tratase de uma pedagogia corporal, relacionada ao viés econômico que marca esse corpo, tornando-o uma peça manipulada pelo capital (FOUCAULT, 2014b).

Parafraseando o filósofo e professor Miroslav Milovic, em sua obra Política $e$ metafísica (2017), trata-se de um período em que o indivíduo é considerado pelas suas possibilidades, virtualidades, em relação à sociedade e não só pelos seus atos. Uma sociedade dominada pela lógica da vigilância panóptica, não mais pelo poder pastoral exercido sobre as almas e pelo poder soberano exercido pelo território.

Eis um poder vital exercido sobre o corpo, à luz da necessidade de majorar a utilidade e docilidade dos corpos, por meio de um sistema de controle eficaz e econômico, assegurado "por procedimentos de poder que caracterizam as disciplinas: anátomo-política do corpo humano" (FOUCAULT, 2014b, p. 150).

Uma sociedade marcada pela lógica do panoptismo, que é exercida por vários agentes sobre os corpos de indivíduos colocados em espaços de controle, seja na escola pelo mestre, seja nas prisões pelo diretor destas, seja em casas de saúde pelos médicos e psiquiatras. São vigilantes, que possuem o poder não apenas de controlar, mas de formar um saber sobre os vigiados, pautado em padrões de normalidade, definidores do que pode ser considerado normal e anormal (FOUCAULT, 2013).

Os corpos passam a ser lidos a partir de uma lógica econômica. Deixou de ser interessante a morte, passa-se a uma lógica de poder que prioriza a vida. Entretanto, isso nem 
sempre representa algo positivo. Deixa de ter sentido matar, uma vez que se precisa dos indivíduos vivos, diante de um valor intrínseco a eles. Um valor que estaria ligado a uma lógica de mão-de-obra, de exploração, de inserção desse indivíduo em uma linha de produção. Protege-se a vida com fins de exploração dos corpos dos indivíduos.

Por sua vez, foi a partir da segunda metade do século XVIII que surgiu a segunda forma de poder sobre a vida, a Biopolítica das populações. Antes de desenvolvê-la, é importante ressaltar que não houve um processo de substituição de uma forma de poder por outra, e sim uma articulação entre estas, o que inclusive foi chamado por Foucault de a era do Biopoder.

Essa nova forma de poder, diferente da anterior, não incide sobre corpos individualizados, estando centrada no coletivo, em populações, no corpo-espécie. O nível biológico ganha centralidade, fazendo com que populações sejam analisadas a partir de sua existência biológica, com o gerenciamento de suas variáveis como nascimento, mortalidade e saúde; determinando-se os seus processos biológicos. Destaca-se, a espécie é colocada no centro de estratégias políticas, no sentido de que o "[...] o homem moderno é um animal em cuja política sua vida de ser vivo está em questão" (FOUCAULT, 2014b, p. 154-155).

Considerando as duas formas de poder destacadas nesta seção, Poder disciplinar e Biopolítica das populações, Foucault (2014b) sustenta a existência de um novo período, a era do Biopoder, que se desenvolve a partir de duas direções: pela disciplina, própria da primeira forma de poder; e pelas regulações de populações. O filósofo destaca que os citados poderes se articulam, formando agenciamentos concretos que constituem a tecnologia de poder no século XIX, sendo o dispositivo de sexualidade um dos mais importantes citados agenciamentos.

Infere-se, portanto, quanto ao objeto do presente artigo, que as concepções foucaultianas, sobre o corpo na Grécia Clássica e nos dois primeiros séculos de nossa era, indicam uma configuração moral sobre o corpo que é dotada de especificidades e não de complementaridades. Conforme se sustentou anteriormente, não é possível vislumbrar, na antiguidade, uma moral sexual sobre o corpo controladora, colonizadora dele, como é possível se identificar e desenvolver na modernidade.

Sendo assim, sustenta-se que as relações de poder relacionadas ao objeto do presente estudo são contemporâneas, da modernidade, citando-se especificamente o dispositivo de sexualidade. Uma lógica empreendedora, produtora e dominadora do corpo e de vidas. Um mecanismo moderno de poder. 
À luz de Michel Foucault, analisando-se a antiguidade e a modernidade, pôde-se identificar uma descontinuidade na moral sexual própria ao paganismo e cristianismo. Até é possível encontrar princípios, noções, que possam estar tanto em um como também em outro, entretanto, estes não possuem os mesmos significados, valores.

Identificaram-se a Igreja e a pastoral cristã como elementos sustentadores de princípios morais controladores do corpo de cada indivíduo, da sexualidade, possuidores de um alcance universal. Em paralelo, na antiguidade não se identificou uma moral unificada, dotada de coerência e que fosse repassada em níveis de imposição. Eis apenas uma suplementação moral comumente aceita (FOUCAULT, 2014c).

A partir do que seria sustentado pela teoria médica da degenerescência, na modernidade, a figura da mulher e do homem foi atrelada a uma perspectiva reprodutiva, a partir da qual a relação considerada legítima é a permeada pelo casamento entre um homem e uma mulher, com fins de reprodução.

Todavia, percebe-se na modernidade uma segunda concepção moral incidente sobre o sexo, corpo e gênero. Trata-se de uma moral relacionada diretamente com interesses políticos e econômicos. Contemporânea ao capitalismo, identifica-se uma lógica de necessidade de mão-de-obra para ocupação de postos de trabalho no campo industrial, ainda emergente.

Para tanto, o instrumento propiciador de mão-de-obra seria exatamente relações entre seres com capacidade reprodutiva. Sendo assim, sustenta-se que essa segunda lógica moral está relacionada à primeira identificada, no sentido de que a segunda se utiliza dos preceitos da primeira. Em outras palavras, para o cumprimento dos interesses políticos e econômicos justificadores da lógica de poder sobre o corpo, atrelar a figura do homem e da mulher em níveis biológicos seria algo útil, tendo em vista que assim se estaria constituindo os elementos necessários para o cumprimento dos citados interesses.

Economicamente e politicamente, é útil para a segunda lógica moral identificada a vinculação do gênero ao sexo considerado biológico, ao corpo sexuado. Legitimando-se, assim, a relação marcada por eles, tendo em vista que somente esta é passível de propiciar a reprodução, um elemento de fundamental relevância à época, um período marcado por um racismo de Estado, que tinha como objetivo a pureza do sangue e uma raça triunfante, o que não seria propiciado por relações que fugissem da citada lógica biologizante do sexo, corpo e gênero. Aquilo que não se adequa à citada lógica seria considerado um desvio, uma perversão sexual, propiciador de males à progenitura ou mesmo do aniquilamento da espécie. 
Percebe-se, assim, um núcleo moral sobre o corpo, que o vincula ao considerado sexo biológico, utilizando-se este como instrumento de definição do gênero de cada indivíduo. Trata-se de uma moral que correlaciona, em níveis de vinculação, o gênero ao sexo biológico, o gênero ao corpo sexuado. Para definir homem e mulher, dever-se-ia olhar para o corpo, este fala, este define, este exala. Uma lógica moral em que o corpo manifesta e o gênero representa.

\section{CONSIDERAÇÕES FINAIS}

Antiguidade e modernidade como períodos dotados de especificidades em relação às construções morais produzidas sobre as práticas sexuais e o uso do corpo, à luz da teoria de Michel Foucault: com a intenção de responder à pergunta de pesquisa proposta, identifica-se uma descontinuidade na perspectiva moral sobre o objeto do presente estudo.

Constatou-se uma ausência de continuidade em relação à ética sexual própria ao cristianismo ou Ocidente moderno, marcada por um controle meticuloso. Caminha-se de uma lógica do cuidado de si para uma dominação efetuada pela pastoral cristã, pautada em uma configuração de poder excessivamente controladora, influenciando os elementos corpo, sexo e gênero.

Destaca-se um dispositivo de poder, próprio da modernidade, o dispositivo de sexualidade; por meio de uma inversão, o referido dispositivo como o responsável pela criação do sexo, em níveis de naturalidade; o processo de naturalização do sexo, sua vinculação a um aspecto biológico como fruto de um complexo de poder.

Para fins de concretização da pesquisa proposta pelo presente artigo, inicialmente desenvolveu-se a construção moral sobre o corpo e as práticas sexuais na antiguidade, aderindo-se à inversão sustentada por Michel Foucault, quem retornou da modernidade para o estudo da antiguidade. Iniciou-se assim pela análise da moral sobre as práticas sexuais na Grécia Clássica e nos dois primeiros séculos de nossa era, a partir da qual se constatou uma espécie de suplementação à moral aceita comumente em sociedade. Suplementação esta que não reproduz a configuração do controle protagonizado na modernidade - segunda seção desenvolvida -, considerando-se a pastoral cristã. Inicia-se um período marcado por princípios morais constritivos sobre o corpo, exercentes de um controle universal, integral e ininterrupto. 
Assim, por meio da referida estrutura, identificam-se especificidades quanto às práticas sexuais nos períodos da antiguidade e modernidade, não sendo possível falar em níveis de continuidade entre estes, diante da configuração própria a cada um desses períodos.

\section{REFERÊNCIAS}

FOUCAULT, Michel. A verdade e as formas jurídicas. Rio de Janeiro: Nau Editora, 2013.

FOUCAULT, Michel. Entrevista de Michel Foucault. In: Ditos \& Escritos IX. Organização, seleção de textos e revisão técnica Manoel Barros da Motta; Trad. Abner Chiquieri. Rio de Janeiro: Forense Universitária, 2014a.

FOUCAULT, Michel. História da sexualidade I: a vontade de saber. Tradução Maria Thereza da Costa Albuquerque e J. A. Guilhon Albuquerque. Rio de Janeiro/ São Paulo: Paz \& Terra, 2014b.

FOUCAULT, Michel. História da sexualidade II: o uso dos prazeres. Tradução Maria Thereza da Costa Albuquerque. Rio de Janeiro/ São Paulo: Paz \& Terra, 2014c.

FOUCAULT, Michel. História da sexualidade III: o cuidado de si. Tradução Maria Thereza da Costa Albuquerque. Rio de Janeiro/ São Paulo: Paz \& Terra, 2014d.

MILOVIC, Miroslav. Política e metafísica. São Paulo: Max Limonad, 2017. 